\title{
Safety of Landiolol Infusion in Patients Undergoing Lung Resection
}

\author{
Kenji Ito' ${ }^{1}$ Masahisa Nozaki' ${ }^{1}$, Reinii Sakamoto ${ }^{1}$, Toshiyasu Suzuki', Ryota Masuda², \\ Masayuki Iwazaki² \\ ${ }^{1}$ Department of Anesthesiology, Tokai University School of Medicine, Isehara, Japan \\ ${ }^{2}$ Department of Thoracic Surgery, Tokai University School of Medicine, Isehara, Japan \\ Email: itokenji@is.icc.u-tokai.ac.jp
}

Received 4 June 2014; revised 9 July 2014; accepted 31 July 2014

Copyright (C) 2014 by authors and Scientific Research Publishing Inc.

This work is licensed under the Creative Commons Attribution International License (CC BY).

http://creativecommons.org/licenses/by/4.0/

(c) (i) Open Access

\begin{abstract}
The efficacy of landiolol hydrochloride, an ultrashort-acting $\beta$-blocker with high $\beta 1$ selectivity, has been confirmed in patients undergoing cardiac surgery in Japan, but there have been few reports about its use for patients having lung resection. We investigated the safety of continuous infusion of landiolol in patients undergoing lung resection. Between May 2008 and May 2011, 200 patients scheduled for lung resection were enrolled. Patients who underwent surgery before the introduction of landiolol in February 2010 were studied retrospectively (Group C) and were compared with those who received landiolol along with surgery (Group L). During the 48-hour study period, the incidence of arrhythmias, changes in heart rate and blood pressure, and occurrence of adverse reactions were examined. The white blood cell count and $C$-reactive protein level were measured before and after surgery to assess the anti-inflammatory effect. The heart rate was significantly lower in Group $L$ throughout the study period. No patient in Group L developed hypotension requiring discontinuation of landiolol therapy, and no respiratory symptoms (including asthma or hypoxemia) were observed. White blood cell and C-reactive protein were significantly increased after surgery in both groups, and there were no between-group differences. Arrhythmic events occurred in 1.1\% (1/99) and 9.2\% (7/76) of Group L and Group C, respectively. One patient in Group C developed ventricular tachycardia. Landiolol can be administered safely during the perioperative period in patients undergoing lung resection.
\end{abstract}

\section{Keywords}

Landiolol, Postoperative Arrhythmia, Lung Resection

\section{Introduction}

Postoperative arrhythmias induced by direct or indirect stimulation can be a problem after thoracic surgery. The 
reported incidence of postoperative arrhythmia in patients having lung resection ranges from $16 \%$ to $85 \%$ [1] [2]. Atrial fibrillation (AF) occurs in $11 \%$ - $16 \%$ of cardiac surgery patients and it may prolong the duration of treatment and/or increase the incidence of cardiac events even over the long term [3]. In addition, several studies have investigated the incidence of AF in noncardiac surgery. Park et al. [4] reported that AF occurs in $12 \%$ and $16 \%$ of patients after video-assisted thoracic surgery (VATS) and thoracotomy, respectively. Based on these results and of various other studies, the American College of Cardiology/American Heart Association (ACC/AHA) guidelines recommend prophylaxis with amiodarone and $\beta$-blockers to prevent $\mathrm{AF}$ [5]. The efficacy of these drugs has recently been demonstrated in randomized clinical trials [6]. However, the conventional parenteral $\beta$-blockers have limited $\beta 1$-selectivity and therefore decrease cardiac output due to their $\beta 2$ effect, as well as causing bronchoconstriction, which often limits their prophylactic use.

Landiolol hydrochloride is an ultrashort-acting $\beta$-blocker with high $\beta 1$ selectivity ( $\beta 1$ : $\beta 2$ affinity $=251: 1)$ [7]. It rarely causes hypotension due to a decrease in cardiac output, and is relatively safe in patients with respiratory disease. The efficacy of landiolol has already been confirmed in patients undergoing cardiac surgery in Japan, but there have been few reports about its use for patients having lung resection [8].

In this study, continuous infusion of landiolol was started in patients with lung cancer at the induction of general anesthesia. Based on anesthesia records, the incidence of adverse reactions and changes in vital signs were assessed to determine the safety of landiolol administration. As a secondary objective, the efficacy of this drug was investigated by recording the occurrence of postoperative arrhythmic events. We also investigated changes in the white blood cell (WBC) count and C-reactive protein (CRP) level because landiolol has been suggested to exert an anti-inflammatory effect as one mechanism by which it prevents arrhythmia [1].

\section{Materials and Methods}

\subsection{Patients}

Patients who underwent surgery before the introduction of landiolol in February 2010 were studied retrospectively (Group C) and were compared with those who received landiolol along with surgery (Group L). Exclusion criteria were high-risk patients with an American Society of Anesthesiologists Physical Status (ASA-PS) score $\geq$ 4 , patients with severe respiratory disease, and patients who received preoperative anti-arrhythmic drugs or $\beta$-blockers.

\subsection{Study Procedures}

The standard of care at our hospital requires patient transfer to the intensive care unit (ICU) after respiratory surgery. These patients generally leave the ICU one day after surgery.

Vital signs were evaluated upon admission to the operating room, and then an epidural catheter was inserted into patients for whom epidural anesthesia was possible. Landiolol infusion was started at a rate of $5 \mu \mathrm{g} / \mathrm{kg} / \mathrm{min}$ immediately before induction of general anesthesia and it was continued until just before patients were discharged from the intensive care unit. Heart rate and blood pressure were measured before and after induction of general anesthesia, at the time of incision, at the beginning and end of differential lung ventilation, after completing surgery, at the time of leaving the operating room, and 24 and 48 hours after the start of infusion. If severe bradycardia and/or hypotension occurred during landiolol infusion, appropriate measures were taken along with the cessation of administration. Arrhythmia was defined as the occurrence of two or more successive premature ventricular contractions (PVC) and/or the occurrence of AF as evidenced by the electrocardiographic monitor, and the time of onset recorded. Anti-arrhythmic drugs were used when required. For WBC and CRP, comparison was performed between the day before and the day after surgery.

This study was approved by the Tokai University Hospital Ethics Committee. All patients who received landiolol therapy provided written informed consent.

\subsection{Statistical Analysis}

The baseline characteristics of the patients were compared using Fisher's exact test and the Mann-Whitney U test. The operating time, anesthetic time, and thoracotomy time were compared using the $t$-test. For heart rate and blood pressure, comparison between before and after general anesthesia was performed with the paired $t$-test, while between-group comparisons were analyzed using the $t$-test. Fisher's exact test was employed to compare the incidence of arrhythmia. 


\section{Results}

One patient in Group L and 20 patients in Group C were excluded because of incomplete data. Four patients from Group C were also excluded because surgery was postponed. The remaining 176 patients (99 in Group L and 76 in Group C) were analyzed for this study. The two groups showed no significant differences of baseline characteristics or the ASA-PS classification. VATS was performed more frequently in Group L than in Group C, but the difference was not significant. The operating time, anesthetic time, and duration of unilateral ventilation did not differ between the two groups (Table 1 ).

In Group L, a significant decrease in heart rate was observed from the induction of anesthesia until the end of surgery (Figure 1). In Group C, however, a significant decrease in heart rate was only noted at the end of surgery. Heart rate increased after the completion of surgery and the difference from the rate before the induction of anesthesia decreased in both groups. Between-group comparison revealed that heart rate was significantly lower in group $\mathrm{L}$ throughout the entire observation period.

Systolic blood pressure decreased in both groups after the induction of anesthesia. In Group L, systolic blood pressure was lower than in Group $\mathrm{C}$ at the post-induction measurement and on leaving the operating room (Figure 2). Diastolic blood pressure was lower in Group L after induction of anesthesia, after the finish of surgery, on leaving the operating theater, and 24 and 48 hours later (Figure 3). Heart rate and systolic/diastolic blood pressure were lower in Group L throughout the entire study period, but cessation of landiolol infusion was not required in any patient.

With regard to arrhythmias, successive PVC were detected in one patient (1.1\%) from Group L, but AF did not occur in this group. In contrast, ventricular tachycardia (VT), AF, and PVC respectively occurred in 1, 2, and 4 patients from Group C (9.2\% in total) (Table 2). The total number of arrhythmic events was significantly lower in Group L $(p=0.02)$. The only arrhythmic event (successive PVC) in Group L occurred at 12 hours. The two patients who developed AF in Group C were in their 70s and it was detected immediately after admission to the intensive care unit. VT occurred at 14 hours and subsided spontaneously. No respiratory symptoms, including asthma and hypoxemia were observed in Group L.

WBC increased significantly in both Group L and Group C, but there was no significant difference between the two groups $(p=0.990)$. CRP also increased significantly in both groups, without a significant betweengroup difference $(p=0.101)$ (Table 3$)$.

Table 1. Baseline characteristics of the two groups.

\begin{tabular}{|c|c|c|c|c|c|}
\hline & \multicolumn{2}{|c|}{ Group L } & \multicolumn{2}{|c|}{ Group C } & \multirow{2}{*}{ Test } \\
\hline & $\mathrm{n}$ & $\%$ & $\mathrm{n}$ & $\%$ & \\
\hline \multicolumn{6}{|l|}{ Sex } \\
\hline Men & 65 & 65.7 & 53 & 69.7 & \multirow{2}{*}{$0.627^{\mathrm{a}}$} \\
\hline Women & 34 & 34.3 & 23 & 30.3 & \\
\hline \multicolumn{6}{|l|}{ Age } \\
\hline$<40$ & 4 & 4.0 & 2 & 2.6 & \multirow{6}{*}{$0.119^{b}$} \\
\hline $40-49$ & 2 & 2.0 & 6 & 7.9 & \\
\hline $50-59$ & 13 & 13.1 & 13 & 17.1 & \\
\hline $60-69$ & 41 & 41.4 & 18 & 23.7 & \\
\hline $70-79$ & 36 & 36.4 & 34 & 44.7 & \\
\hline$\geq 80$ & 3 & 3.0 & 3 & 3.9 & \\
\hline \multicolumn{6}{|l|}{ Surgical procedure } \\
\hline VATS & 71 & 71.7 & 51 & 67.1 & \multirow{2}{*}{$0.505^{\mathrm{a}}$} \\
\hline Thoracotomy & 27 & 27.3 & 25 & 32.9 & \\
\hline \multicolumn{6}{|l|}{ ASA class } \\
\hline 1 & 41 & 41.4 & 29 & 38.2 & \multirow{3}{*}{$0.614^{\mathrm{b}}$} \\
\hline 2 & 44 & 44.4 & 32 & 42.1 & \\
\hline 3 & 14 & 14.1 & 15 & 19.7 & \\
\hline
\end{tabular}

${ }^{\mathrm{a}}$ Fisher's exact test; ${ }^{\mathrm{b}}$ Mann-Whitney U test; VATS: video-assisted thoracoscopic surgery; ASA: American Society of Anesthesiologists. 


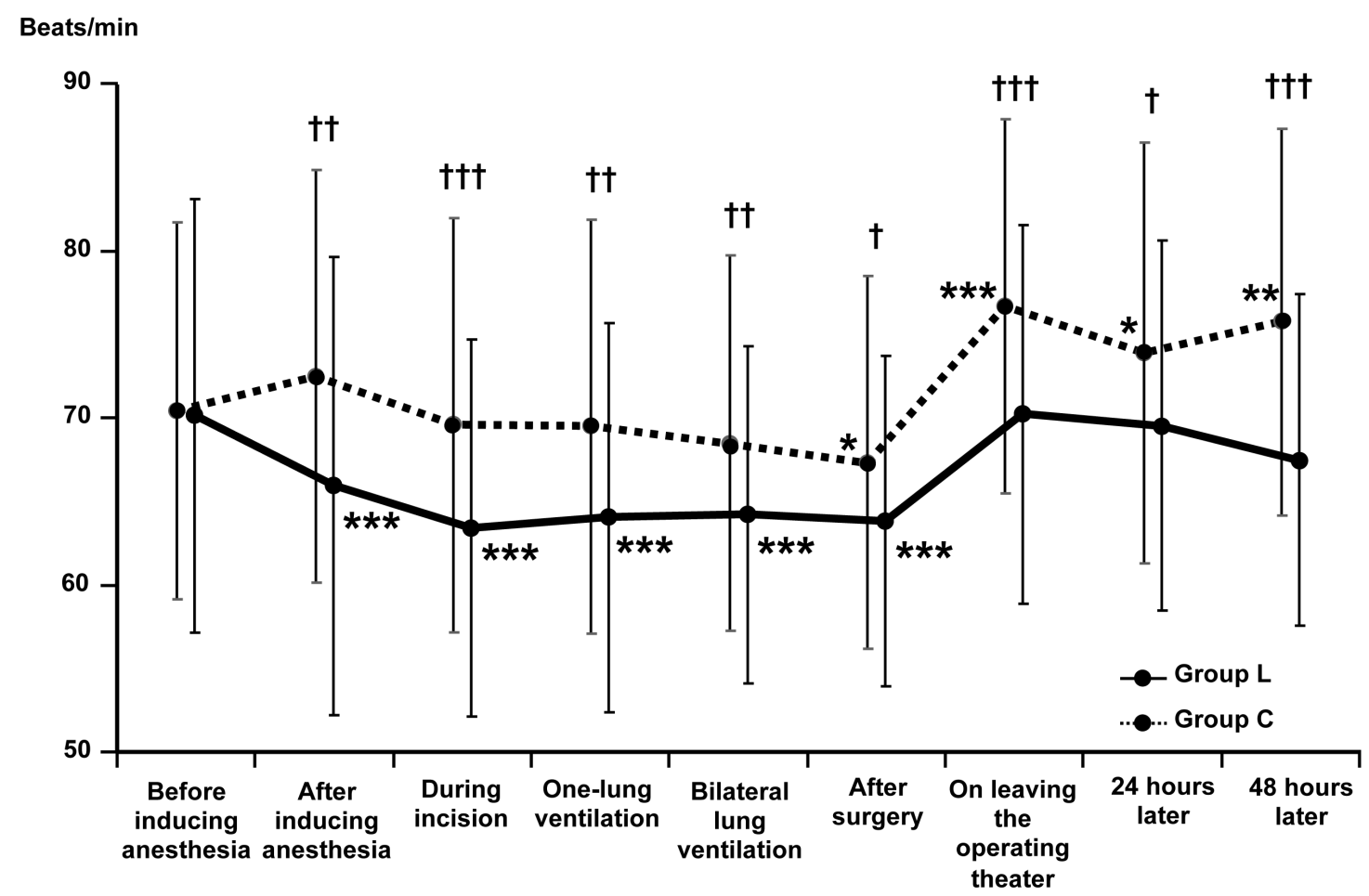

Figure 1. Changes in heart rate from immediatelybefore induction of general anesthesia until 48 hours later. Comparison between before induction of general anesthesia and each time point by the paired $t$-test: ${ }^{*} p<0.05,{ }^{* *} p<$ $0.01,{ }^{* * *} p<0.001$. Between-group difference at each time by the $t$-test: ${ }^{+} p<0.05,{ }^{++} p<0.01,{ }^{++} p<0.001$.

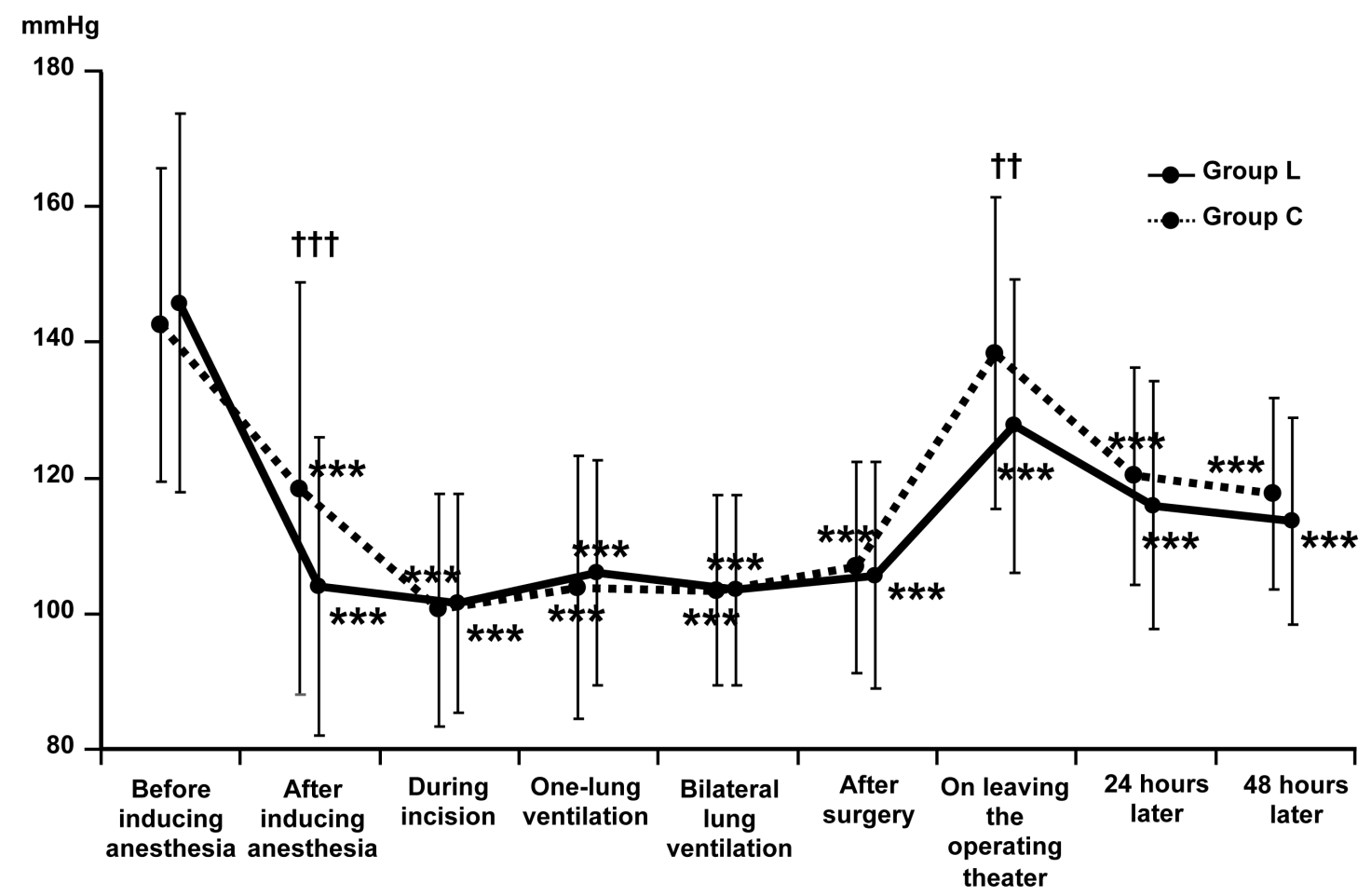

Figure 2. Changes insystolic blood pressure from immediatelybefore induction of general anesthesia until 48 hours later. Comparison between before induction of general anesthesia and each time point by the paired $t$-test: ${ }^{* * *} p<$ 0.001 . Between-group difference at each time by the $t$-test: ${ }^{++} p<0.01,{ }^{+++} p<0.001$. 


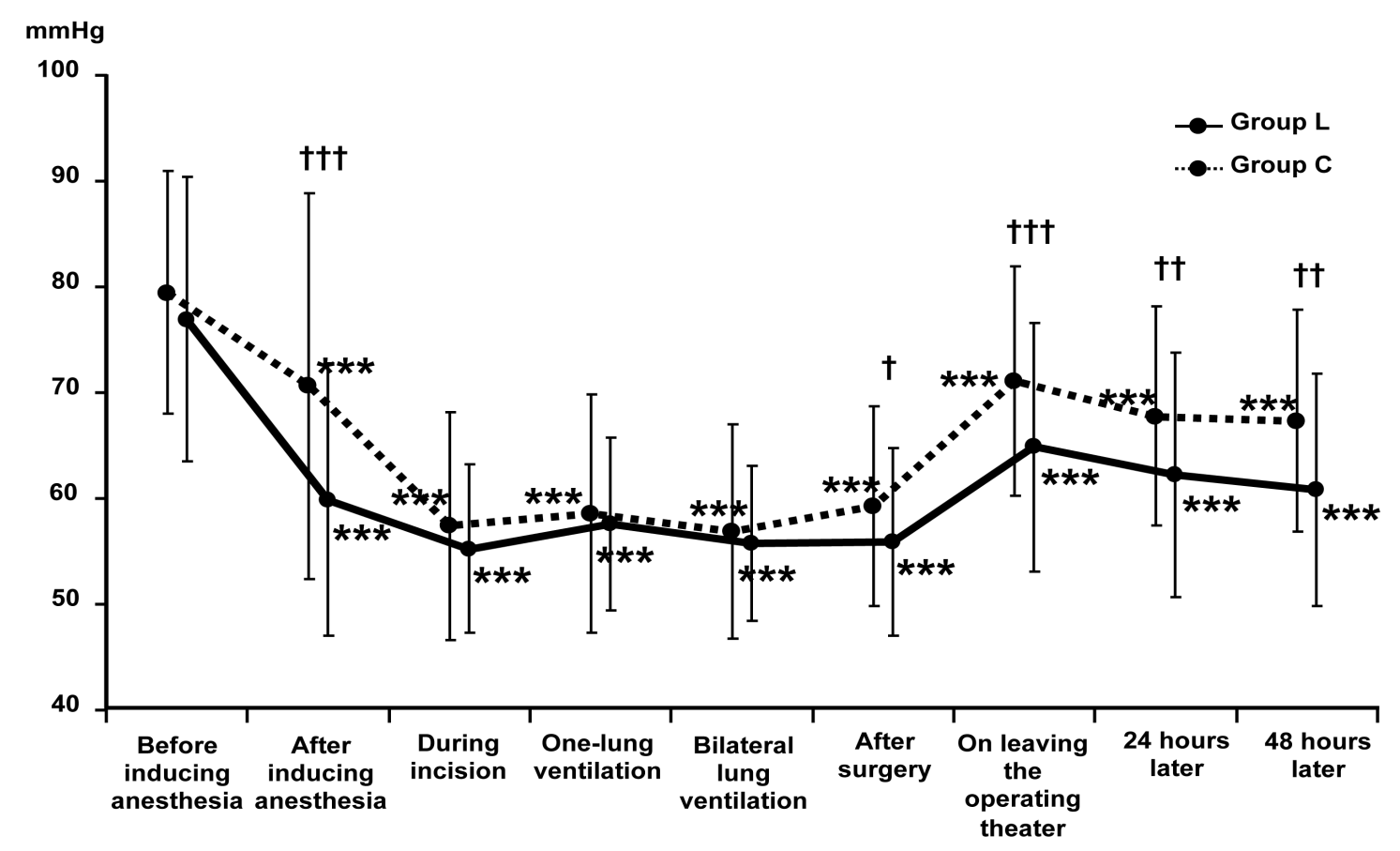

Figure 3. Changes in diastolic blood pressure from immediatelybefore induction of general anesthesia until 48 hourslater. Comparison between before induction of general anesthesia and each time point by the paired $t$-test: ${ }^{* * *} p<$ 0.001 . Between-group difference at each time by the $t$-test: ${ }^{+} p<0.05,{ }^{++} p<0.01,{ }^{++} p<0.001$.

\section{Table 2. Incidence of arrhythmia.}

\begin{tabular}{ccc}
\hline & Group L $(\mathrm{n}=99)$ & Group C $(\mathrm{n}=76)$ \\
PVC & 1 & 4 \\
AF & 0 & 2 \\
VT & 0 & $7^{*}$ \\
Total & 1 & 1
\end{tabular}

PVC: premature ventricular contractions; AF: atrial fibrillation; VT: ventricular tachycardia. ${ }^{*}$ Fisher's exact test, $p=0.02$. Only successive PVCs were included.

Table 3. Changes in WBC and CRP from before to 24 hours after surgery.

\begin{tabular}{cccccccccc}
\hline & \multicolumn{3}{c}{ Group L } & \multicolumn{3}{c}{ Group C } & & ANOVA \\
\hline & Mean & SD & Paired $t$-test & Mean & SD & $\begin{array}{c}\text { Paired } \\
t \text {-test }\end{array}$ & t-test & $\begin{array}{c}\text { Between-group } \\
\text { difference }\end{array}$ & Inter-action \\
\hline WBC & & & & & & & & & \\
Pre-op & 6105 & 1818 & - & 6009 & 1568 & - & 0.714 & & 0.540 \\
$\begin{array}{c}24 \text { hours } \\
\text { post-op }\end{array}$ & 9196 & 2643 & $<0.001$ & 9299 & 2310 & $<0.001$ & 0.788 & & \\
$\begin{array}{c}\text { CRP } \\
\text { Pre-op }\end{array}$ & 0.22 & 0.39 & - & 0.19 & 0.37 & - & 0.590 & & \\
$\begin{array}{c}24 \text { hours } \\
\text { post-op }\end{array}$ & 10.22 & 6.33 & $<0.001$ & 8.62 & 6.53 & $<0.001$ & 0.104 & 0.101 & \\
\hline
\end{tabular}

WBC: white blood cell; CRP: C-reactive protein; SD: standard deviation; ANOVA: analysis of variance. Before versus 24 hours after surgery; $p<0.001$ by the $t$-test. 


\section{Discussion}

Previous studies have shown that oral $\beta$-blocker therapy can prevent AF after lung resection [9] [10], but these studies also revealed a decline in blood pressure due to low $\beta$-1 selectivity. Landiolol is a highly adjustable $\beta$-blocker because it is administered intravenously and has a very short half-life of about four minutes. Nakano et al. [11] also reported that continuous landiolol infusion is safe during open-heart surgery. In fact, none of the patients in Group L experienced severe hypotension or bradycardia that required discontinuation of landiolol therapy. In addition, this drug could be administered safely in combination with intraoperative remifentanil in the present study.

The appropriate dosage as well as the timing of initiation and duration of landiolol therapy have not yet been established. Based on the findings of the current study, perioperative administration of landiolol should accompany the patient explanation and consent form for a potential blood pressure treatment as well as for treatment not covered by insurance. Nevertheless, early introduction appears to be more effective as a decrease in heart rate could be translated into a decrease in the workload of the heart, with the markers for myocardial damage being significantly lower in landiolol-treated patients as reported by Sezai et al. [12]. Okita et al. [8] administered landiolol ( $5 \mu \mathrm{g} / \mathrm{kg} / \mathrm{min}$ ) from the induction of anesthesia until completion of surgery and found that the incidence of postoperative AF was 5.2\%, which was significantly lower than in patients who did not receive this drug. Under general anesthesia, tachycardia is more likely to occur, especially during intubation and/or extubation. In the present study, we started landiolol therapy immediately before the induction of general anesthesia because an inflammatory response was expected when the surgical procedures were carried out. As a result, the heart rate was significantly lower in Group L throughout the study. It is noteworthy that the heart rate decreased in Group L after induction of general anesthesia, while it increased in the control group. This indicates that stress due to intubation and/or surgical procedures was lower in Group L. The finding that the heart rate was significantly lower in Group L even after landiolol infusion was ceased suggests that early introduction of this drug alleviated stress on the heart. This study employed landiolol infusion at $5 \mu \mathrm{g} / \mathrm{kg} / \mathrm{min}$, but reports on cardiovascular surgery indicate that it exerts a significant effect when infused at only $2 \mu \mathrm{g} / \mathrm{kg} / \mathrm{min}$ [9] [13]. As a significant reduction in cardiac output during landiolol infusion has been reported in patients with a low cardiac output (ejection fraction < 50\%) [14], patients with an ASA-PS score of 4 or higher were excluded from the present study. Further studies need to be undertaken to determine the optimum infusion rate.

In many previous studies, the incidence of arrhythmia was assessed purely from the occurrence of AF, which accounts for $11 \%$ to $16 \%$ of the total. In this study, AF occurred in $0 \%$ and $2.6 \%$ of Group L and Group C, respectively, which is far below the levels reported so far. This may have been because patients were only followed up for 48 hours postoperatively despite the fact that arrhythmic events including AF can often occur 70 hours after surgery, as reported by Shiroya et al. [7]. Cardinale et al. [15] also reported that the peak of AF onset was on the second postoperative day. Further studies with a sufficient observation period are warranted to verify our findings.

Okita et al. [8] identified age and the operating time as risk factors for postoperative AF. They also reported that AF was especially more frequent when the operating time was longer than six hours. In the present study, operating time was $119.97 \pm 56.07 \mathrm{~min}$ and $121.97 \pm 51.60 \mathrm{~min}$ in Group L and Group C, respectively, and such relatively short operating times might have contributed to our favorable results.

The less invasive procedures that were predominantly performed in our series may be another explanation. That is, about $70 \%$ of our patients underwent endoscopic surgery, which does not need a large incision, so their postoperative pain could be well controlled. Pain stimulates the sympathetic nervous system and this leads to catecholamine secretion. It is believed that catecholamine affects $\beta 1$ receptors of the heart and thereby increases heart rate, which may lead to the onset of AF. Thus, it seems reasonable to speculate that good control of pain might have contributed to the fewer number of AF cases in the population of the present study. There are however conflicting reports about the reduction in postsurgical complications due to VATS [16] [17] [18], as well as other reports about reduction of postoperative AF thanks to thoracic epidural anesthesia in the setting of cardiovascular surgery. Further research on these issues is needed, and such studies may benefit by incorporating preoperative atrial natriuretic peptide and B-type natriuretic peptide, which Nojiri et al. [19] reported could be a predictive factor for the occurrence of postoperative AF.

Regardless, infusion of landiolol seemed to be beneficial, taking into account the fact that arrhythmias, including ventricular tachycardia and AF, were significantly more frequent in Group C. Our favorable results may 
also have been due to the short operating time, which enabled us to use a relatively small volume of fluid and less anesthetic. Furthermore, postoperative pain was probably alleviated by a minimally invasive approach in the $70 \%$ of surgical procedures performed with endoscopic techniques. Nevertheless, the significantly higher incidence of arrhythmic events in Group C versus Groups L supports the usefulness of landiolol. As the general population ages, especially in developed countries, patients become older as well. This means that the anesthetic risk may be higher in the future, so that preventive medicine will be of the utmost importance.

We could not identify an anti-inflammatory effect of landiolol based on measurement of WBC and CRP. Sezai et al. [1] studied multiple parameters, including cytokines, and concluded that the anti-inflammatory effect of landiolol contributed to a lower incidence of postoperative AF. In the present study, WBC and CRP were significantly elevated after surgery in both groups, indicating that the operations caused inflammation to a similar extent. However, further investigations employing more parameters should be considered to elucidate the anti-inflammatory effect of landiolol.

The limitations of the present study included its single-center, retrospective design and the relatively short observation period. Further prospective studies need to be undertaken with an observation period of at least 70 hours so as to verify our findings. In addition, the sample size was relatively small in the current study. Future studies with a larger cohort of patients would provide more conclusive results in terms of the effectiveness of landiolol treatment on the incidence of AF.

\section{Conclusion}

We evaluated the safety of perioperative landiolol infusion in patients undergoing lung resection. Our study indicates that landiolol can be administered safely by continuous infusion for 24 hours starting immediately after the induction of general anesthesia, without adverse reactions requiring specific treatment or treatment cessation. Further studies are warranted to clarify the optimum infusion rate, as well as the efficacy aspects of the drug, including anti-inflammatory effects.

\section{References}

[1] Sezai, A., Shiono, M. and Kato, J. (2010) Expectation for Ultra Short Acting Beta-Blocker in Cardiac Surgery: New Evidence from the PASCAL Trial. Rinsyomasui (Journal of Clinical Anesthesia), 34, 1243-1250 (in Japanese).

[2] Villareal, R.P., Hariharan, R., Liu, B.C., Kar, B., Lee, V.V., Elayda, M., Lopez, J.A., Rasekh, A., Wilson, J.M. and Massumi, A. (2004) Postoperative Atrial Fibrillation and Mortality after Coronary Artery Bypass Surgery. Journal of the American College of Cardiology, 43, 742-748. http://dx.doi.org/10.1016/j.jacc.2003.11.023

[3] Mariscalco, G., Klersy, C., Zanobini, M., Banach, M., Ferrarese, S., Borsani, P., Cantore, C., Biglioli, P. and Sala, A. (2008) Atrial Fibrillation after Isolated Coronary Surgery Affects Late Survival. Circulation, 118, 1612-1618.

[4] Park, B.J., Zhang, H., Rusch, V.W. and Amar, D. (2007) Video-Assisted Thoracic Surgery Does Not Reduce the Incidence of Postoperative Atrial Fibrillation after Pulmonary Lobectomy. Journal of Thoracic and Cardiovascular Surgery, 133, 775-779. http://dx.doi.org/10.1016/j.jtcvs.2006.09.022

[5] Fuster, V., Rydén, L.E., Cannom, D.S., Crijns, H.J., Curtis, A.B., Ellenbogen, K.A., Halperin, J.L., Le Heuzey, J.Y., Kay, G.N., Lowe, J.E., Olsson, S.B., Prystowsky, E.N., Tamargo, J.L., Wann, S., Smith, S.C. Jr, Jacobs, A.K., Adams, C.D., Anderson, J.L., Antman, E.M., Halperin, J.L., Hunt, S.A., Nishimura, R., Ornato, J.P., Page, R.L., Riegel, B., Priori, S.G., Blanc, J.J., Budaj, A., Camm, A.J., Dean, V., Deckers, J.W., Despres, C., Dickstein, K., Lekakis, J., McGregor, K., Metra, M., Morais, J., Osterspey, A., Tamargo, J.L., Zamorano, J.L., American College of Cardiology/American Heart Association Task Force on Practice Guidelines, European Society of Cardiology Committee for Practice Guidelines, European Heart Rhythm Association, and Heart Rhythm Society (2006) ACC/AHA/ESC 2006 Guidelines for the Management of Patients with Atrial Fibrillation: A Report of the American College of Cardiology/American Heart Association Task Force on Practice Guidelines and the European Society of Cardiology Committee for Practice Guidelines (Writing Committee to Revise the 2001 Guidelines for the Management of Patients With Atrial Fibrillation): Developed in Collaboration with the European Heart Rhythm Association and the Heart Rhythm Society. Circulation, 114, 257-354. http://dx.doi.org/10.1161/CIRCULATIONAHA.106.177292

[6] Crystal, E., Connolly, S.J., Sleik, K., Ginger, T.J. and Yusuf, S. (2002) Interventions on Prevention of Postoperative Atrial Fibrillation in Patients Undergoing Heart Surgery: A Meta-Analysis. Circulation, 106, 75-80. http://dx.doi.org/10.1161/01.CIR.0000021113.44111.3E

[7] Shiroya, T., Ichioka, Y., Yoshida, K., Nishijima, K., Omawari, N., Naka, M., Kondo, K. and Kohjimoto, Y. (1997) Pharmacological Studies of ONO-1101 as a $\beta$-blocking Agent with High $\beta 1$-Selectivity and Ultra-Short Duration of Action. Kiso to Rinsho (Clinical Report), 31, 2913-2923 (in Japanese). 
[8] Okita, T., Uji, M., Shinjo, T., Morioka, M., Kumano, H., Ishimura, N. and Nishiwada, M. (2008) Use of Landiolol Hydrochloride for the Prevention of Atrial Fibrillation after Lung Resection. Masui (Japanese Journal of Anesthesiology), 57, 953-958 (in Japanese).

[9] Jakobsen, C.J., Bille, S., Ahlburg, P., Rybro, L., Hjortholm, K. and Andresen, E.B. (1997) Perioperative Metoprolol Reduces the Frequency of Arterial Fibrillation after Thoracotomy for Lung Resection. Journal of Cardiothoracic and Vascular Anesthesia, 11, 746-751. http://dx.doi.org/10.1016/S1053-0770(97)90169-5

[10] Bayliff, C.D., Massel, D.R., Inculet, R.I., Malthaner, R.A., Quinton, S.D., Powell, F.S. and Kennedy, R.S. (1999) Propranolol for the Prevention of Postoperative Arrhythmias in General Thoracic Surgery. Annals of Thoracic Surgery, 67, 182-186. http://dx.doi.org/10.1016/S0003-4975(98)01226-0

[11] Nakano, T., Shimizu, K., Kawashima, O., Kamiyoshihara, M., Nagashima, T., Ibe, T. and Takeyoshi, I. (2012) Effect of Landiolol Hydrochloride, an Ultra-Short-Acting Beta 1-Selective Blocker, on Supraventricular Tachycardia, Atrial Fibrillation and Flutter after Pulmonary Resection. Journal of Clinical Pharmacy and Therapeutics, 37, 431-435.

[12] Sezai, A., Minami, K., Nakai, T., Hata, M., Yoshitake, I., Wakui, S., Shiono, M. and Hirayama, A. (2011) Landiolol Hydrochloride for Prevention of Atrial Fibrillation after Coronary Artery Bypass Grafting: New Evidence from the PASCAL Trial. Journal of Thoracic and Cardiovascular Surgery, 141, 1478-1487. http://dx.doi.org/10.1016/j.jtcvs.2010.10.045

[13] Sakamoto, A., Kitakaze, M., Takamoto, S., Namiki, A., Kasanuki, H., Hosoda, S. and JL-KNIGHT Study Group (2012) Landiolol, an Ultra-Short-Acting $\beta(1)$-Blocker, More Effectively Terminates Atrial Fibrillation Than Diltiazem after Oopen Heart Surgery. Circulation Journal, 76, 1097-1101. http://dx.doi.org/10.1253/circj.CJ-11-1332

[14] Goto, K., Hagiwara, S., Hidaka, S., Yamamoto, S., Kusaka, J., Yasuda, N., Shingu, C. and Noguchi, T. (2010) The Effect of Landiolol on Cerebral Blood Flow in Patients Undergoing Off-Pump Coronary Artery Bypass Surgery. Journal of Anesthesia, 24, 11-16. http://dx.doi.org/10.1007/s00540-009-0849-X

[15] Cardinale, D., Colombo, A., Sandri, M.T., Lamantia, G., Colombo, N., Civelli, M., Salvatici, M., Veronesi, G., Veglia, F., Fiorentini, C., Spaggiari, L. and Cipolla, C.M. (2007) Increased Perioperative N-Terminal Pro-B-Type Natriuretic Peptide Levels Predict Atrial Fibrillation after Thoracic Surgery for Lung Cancer. Circulation, 115, 1339-1344. http://dx.doi.org/10.1161/CIRCULATIONAHA.106.647008

[16] Kim, D.H. and Park, J.C. (2007) Completion Sleeve Pneumonectomy for Suture Line Recurrence of Lung Cancer after Sleeve Lobectomy. Thoracic and Cardiovascular Surgeon, 55, 512-514. http://dx.doi.org/10.1055/s-2007-989289

[17] Hollings, D.D., Higgins, R.S., Faber, L.P., Warren, W.H., Liptay, M.J., Basu, S. and Kim, A.W. (2010) Age Is a Strong Risk Factor for Atrial Fibrillation after Pulmonary Lobectomy. American Journal of Surgery, 199, 558-561. http://dx.doi.org/10.1016/j.amjsurg.2009.11.006

[18] Kikuchi, Y., Ushijima, T., Ikeda, C., Takata, M. and Yamamoto, Y. (2009) Concomitant Use of Epidural Anesthesia in Off-Pump Coronary Artery Bypass Grafting for Effective Suppression of Atrial Fibrillation. Tokyo Ika Daigaku Zasshi (Journal of Tokyo Medical College), 67, 439-449 (in Japanse).

[19] Nojiri, T., Maeda, H., Takeuchi, Y., Funakoshi, Y., Kimura, T., Maekura, R., Yamamoto, K. and Okumura, M. (2010) Predictive Value of B-Type Natriuretic Peptide for Postoperative Atrial Fibrillation Following Pulmonary Resection for Lung Cancer. European Journal of Cardio-Thoracic Surgery, 37, 787-791.

http://dx.doi.org/10.1016/j.ejcts.2009.09.043 
Scientific Research Publishing (SCIRP) is one of the largest Open Access journal publishers. It is currently publishing more than 200 open access, online, peer-reviewed journals covering a wide range of academic disciplines. SCIRP serves the worldwide academic communities and contributes to the progress and application of science with its publication.

Other selected journals from SCIRP are listed as below. Submit your manuscript to us via either submit@scirp.org or Online Submission Portal.
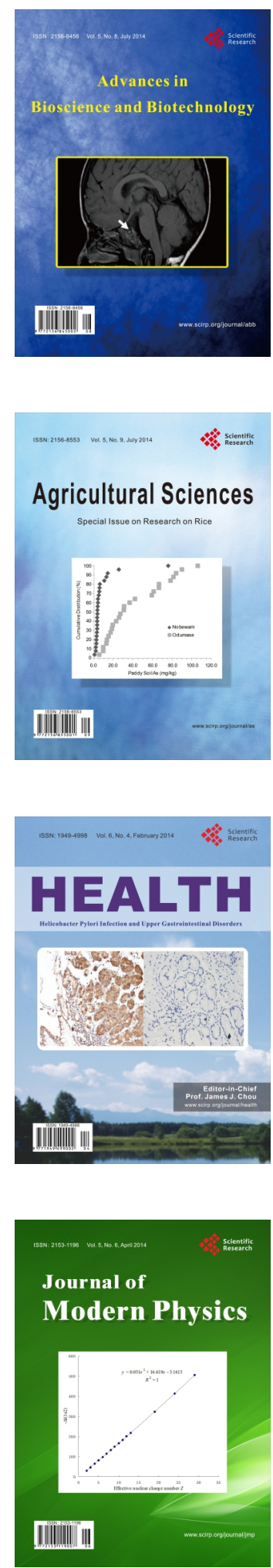
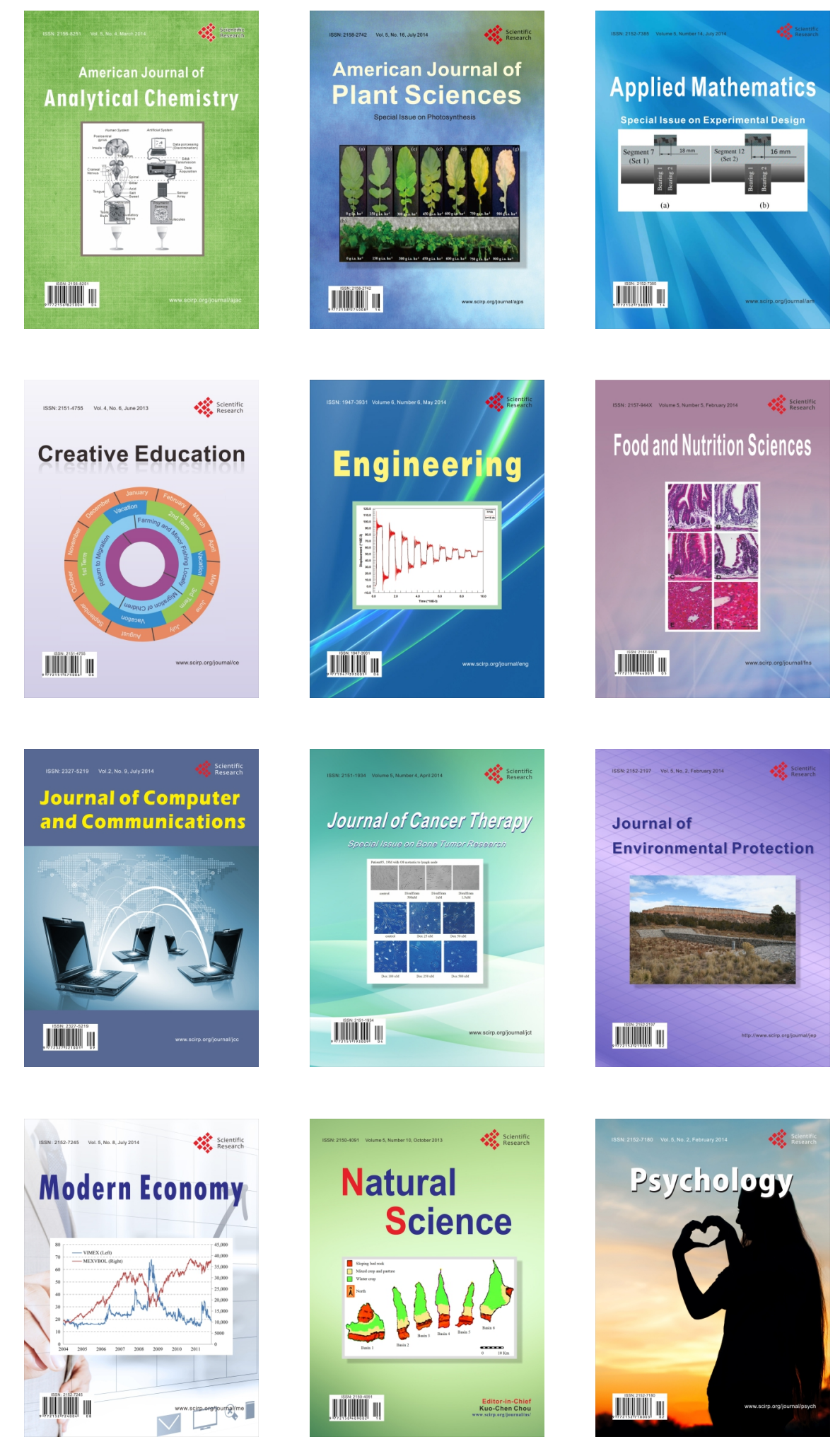